\title{
Níveis de Lisina Digestível para Pintos de Corte Machos na Fase de 1 a 21 Dias de Idade 1 Giane da Silva Conhalato ${ }^{2}$, Juarez Lopes Donzele ${ }^{3}$, Horácio Santiago Rostagno ${ }^{3}$, Luiz Fernando Teixeira Albino ${ }^{3}$, Rita Flávia Miranda de Oliveira ${ }^{3}$
}

\begin{abstract}
RESUMO - O objetivo deste trabalho foi determinar a exigência de lisina digestível para pintos de corte machos na fase de 1 a 21 dias de idade. Seiscentos pintos de corte machos Hubbard, com peso médio inicial de $48 \mathrm{~g}$, foram distribuídos em delineamento experimental em blocos casualizados, com cinco tratamentos, seis repetições e 20 aves por unidade experimental. Os tratamentos corresponderam à ração basal, com 20,85\% de proteína bruta e $3000 \mathrm{kcal}$ de EM/kg, atendendo às exigências de proteína, energia, cálcio, fósforo e aminoácidos, exceto lisina, suplementada com cinco níveis de L-lisina, resultando em rações com 0,84; 0,93; 1,02; 1,11; e 1,20\% de lisina digestível na ração. A digestibilidade verdadeira dos aminoácidos na ração basal foi determinada por meio de ensaio de digestibilidade com galos Leghorn cecectomizados. Os níveis de lisina digestível da ração influenciaram o ganho de peso, a conversão alimentar, o consumo de lisina, o teor de extrato etéreo da carcaça e a taxa de deposição de proteína e gordura na carcaça. Porém, não houve efeito sobre o consumo de ração e na concentração de ácido úrico no soro sangüíneo e proteína bruta, matéria seca e água na carcaça. Com base nos resultados de GP, CA e taxa de deposição de proteína na carcaça, as exigências de lisina digestível foram estimadas em 1,05; 1,03; e 1,08\%, respectivamente.
\end{abstract}

Palavras-chave: lisina, pintos de corte, fase inicial, machos

\section{Levels of Digestible Lysine for Male Broilers in the Phase from 1 to 21 Days}

\begin{abstract}
The objective of this experiment was to determine the digestible lysine requirement for male broilers from 1 to 21 days. Six hundred male broiler chicks, Hubbard, with an average weight of $48 \mathrm{~g}$ were allotted to randomized blocks experimental design with five treatments, six replicates and 20 chicks per experimental unit. The treatments corresponded to the basal diet, with $20.85 \%$ of crude protein and $3000 \mathrm{kcal}$ of ME/ $\mathrm{kg}$, attending the requirements of protein, energy, calcium, phosphorus and amino acids, except lysine supplemented with five L-lysine levels, resulting on diets with .84, .93, 1.02, 1.11, and 1.20\% of digestible lysine in the diet. The true amino acid digestibility in the basal diet was determined by means of a digestibility trial with cecectomized Leghorn roosters. The digestible lysine levels in the diet influenced the weight gain, feed:gain ratio, lysine intake, the ether extract content of the carcass and the protein and fat deposition rate in the carcass. However, there was no effect on diet intake and the concentration of uric acid in the blood serum and crude protein, dry matter and water of the carcass. Based on the results of WG, F:G and protein deposition rate in the carcass, the digestible lysine requirements were estimated in $1.05,1.03$, and $1.08 \%$, respectively.
\end{abstract}

Key Words: lysine, broiler chicks, initial phase, male

\section{Introdução}

As rações de aves formuladas principalmente à base de milho e farelo de soja são geralmente deficientes em certos aminoácidos. Por este fato, há especial interesse em se determinar a exigência dos aminoácidos (lisina, metionina, metionina + cistina, treonina, triptofano, entre outros) para frangos de corte, a fim de se obterem melhores resultados de desempenho e qualidade da carcaça.

A lisina, por ser considerada o segundo aminoácido limitante para frangos de corte, tem tido sua exigência largamente estudada. No entanto, diversos fato- res têm influenciado o requerimento de lisina, como estresse, linhagem, ambiente térmico, teor de proteína da ração, energia digestível e, principalmente, os alimentos utilizados nas formulações.

Com o objetivo de maximizar o uso dos nutrientes nas rações, algumas tabelas de exigência nutricional foram elaboradas (ROSTAGNO et al., 1983; NATIONAL RESEARCH COUNCIL - NRC, 1994). No entanto, algumas recomendações para aminoácidos são ainda divergentes.

O NATIONAL RESEARCH COUNCIL - NRC (1994) recomenda 1,0\% de lisina total para frangos de corte na fase de 1 a 21 dias com rações com $3200 \mathrm{kcal}$ 
de EM, o que corresponde a $0,313 \%$ de lisina total por $1000 \mathrm{kcal}$ de EM; já ROSTAGNO et al. (1983) recomendam $0,368 \%$ de lisina total por $1000 \mathrm{kcal}$ de EM da ração para frangos com idade de 1 a 28 dias. Em trabalhos recentes, Barboza (1996), citado por ROSTAGNO et al. (1996), recomenda $1,18 \%$ de lisina total para frangos de corte machos na fase de 1 a 21 dias de idade. ROSTAGNO et al. (1996) também recomendam 1,165 e $1,056 \%$ de lisina total e digestível, respectivamente, para frangos de corte na fase de 1 a 21 dias de idade.

Logo, a variação nas recomendações de exigência de lisina, para frangos de corte na fase inicial, e a escassez de recomendações com base em lisina digestível constituíram a base desta pesquisa. Com base no exposto, conduziu-se este trabalho para determinar a exigência de lisina digestível para pintos de corte machos na fase de 1 a 21 dias de idade.

\section{Material e Métodos}

O experimento foi conduzido na Seção de Avicultura do Departamento de Zootecnia, do Centro de Ciências Agrárias da Universidade Federal de Viçosa, no período de 22 de novembro a 12 de dezembro de 1996.

Durante todo o período experimental, foi adotado o programa de luz contínuo (24 horas de luz natural + artificial). Para aquecimento artificial dos pintos do $1^{\mathrm{O}}$ ao $14^{\mathrm{O}}$ dia, utilizou-se lâmpada de infravermelho de $250 \mathrm{~W} /$ boxe, com altura regulável.

As variáveis temperatura e umidade relativa do ar, durante o período experimental, foram mensuradas por termômetro de máxima e mínima e termômetro de bulbo úmido e bulbo seco, respectivamente, instalados no interior do galpão. As temperaturas máxima e mínima médias do ar e a umidade relativa foram de $27,43 \pm 0,28^{\circ} \mathrm{C} ; 20,28 \pm 1,14^{\circ} \mathrm{C} ;$ e $79,7 \pm 3,27 \%$, respectivamente, para o período de 1 a 7 dias; $28,07 \pm 0,71^{\circ} \mathrm{C} ; 22,64 \pm 1,00^{\circ} \mathrm{C}$; e $78,70 \pm 4,67 \%$, respectivamente, para o período de 8 a 14 dias; e $27,86 \pm 1,57^{\circ} \mathrm{C} ; 21,23 \pm 0,71^{\circ} \mathrm{C}$; e $83,10 \pm 0,21 \%$, respectivamente, para o período de 15 a 21 dias de idade. Foram utilizados 600 pintos de corte machos da linhagem Hubbard, vacinados contra as doenças de Marek e Bouba Aviária, com peso médio inicial de $48 \mathrm{~g}$, no período de 1 a 21 dias de idade.

Os animais receberam ração à base de milho, farelo de soja e glúten de milho, com 20,85\% PB e $3000 \mathrm{kcal}$ de EM (Tabela 1), formulada para atender às exigências nutricionais das aves em proteína, energia, cálcio e fósforo, segundo ROSTAGNO et al.
(1996), e de aminoácidos, exceto lisina, segundo o NATIONAL RESEARCH COUNCIL - NRC (1994). A ração basal foi suplementada com cinco níveis de L-lisina $\mathrm{HCl} 78,4 \%(0,00 ; 0,11 ; 0,23 ; 0,34$; e $0,45 \%)$ em substituição ao caulim, resultando em rações com 0,95 e $0,84 \% ; 1,05$ e $0,93 \% ; 1,15$ e $1,02 \% ; 1,25$ e $1,11 \%$; e 1,35 e $1,20 \%$ de lisina total e digestível, respectivamente. A composição dos ingredientes em aminoácidos totais e da ração basal em aminoácidos totais e digestíveis encontra-se na Tabela 2. A digestibilidade dos aminoácidos sintéticos adicionados à ração foi considerada $100 \%$.

A digestibilidade verdadeira dos aminoácidos na ração basal foi determinada por meio de ensaio de

Tabela 1 - Composição percentual da ração basal Table 1 - Percent composition of basal diet

\begin{tabular}{|c|c|}
\hline Ingrediente (Ingredient) & $(\%)$ \\
\hline Milho (Corn) & 57,835 \\
\hline Farelo de soja (Soybean meal) & 27,700 \\
\hline Glúten de milho (Corn gluten) & 7,000 \\
\hline Fosfato bicálcico (Dicalcium phosphate) & 1,704 \\
\hline Calcário (Limestone) & 1,428 \\
\hline Óleo (Oil) & 1,574 \\
\hline Sal comum (Salt) & 0,405 \\
\hline Mistura vitamínica (Vitamin mix) ${ }^{1}$ & 0,100 \\
\hline Mistura mineral (Mineral mix) ${ }^{2}$ & 0,050 \\
\hline Cocciden & 0,050 \\
\hline $\mathrm{BHT}$ & 0,010 \\
\hline Cloreto de colina (Coline chlorate) & 0,125 \\
\hline Bacitracina de zinco (Zinc bacitracine) & 0,020 \\
\hline Caulin & 1,447 \\
\hline L-Lisina $(L-L y$ sine $)(78,4 \%)$ & 0,000 \\
\hline DL - Metionina (DL-Methionine) $(99 \%)$ & 0,193 \\
\hline L-Treonina (L-Threonine) $(98,5 \%)$ & 0,177 \\
\hline L-Isoleucina (L-Isoleucine) $(99 \%)$ & 0,075 \\
\hline L-Valina (L-Valine) $(99 \%)$ & 0,107 \\
\hline \multicolumn{2}{|l|}{ Composição calculada } \\
\hline \multicolumn{2}{|l|}{ Calculated composition } \\
\hline Lisina total (Total lysine), $\%$ & 0,950 \\
\hline Lisina digestível (Digestible lysine), \% & 0,840 \\
\hline Proteína bruta (Crude protein), \% & 20,850 \\
\hline Energia metabolizável (kcal/kg) & 3000 \\
\hline \multicolumn{2}{|l|}{ Metabolizable energy } \\
\hline Cálcio (Calcium), \% & 0,995 \\
\hline Fósforo disponível (Available phosphorus), \% & 0,453 \\
\hline Sódio (Sodium), \% & 0,200 \\
\hline \multicolumn{2}{|c|}{$\begin{array}{l}{ }^{1} \text { Conteúdo/kg (Containing/kg) - vit. A - } 15.000 .000 \text { UI, vit. } \mathrm{D}_{3}- \\
1500.000 \mathrm{UI} /(\mathrm{IU}) \text {, vit. } \mathrm{E}-15.000 \mathrm{UI} /(\mathrm{IU}) \text {, vit. } \mathrm{B}_{1}-2,0 \mathrm{~g} \text {, vit. } \mathrm{B}_{2}-4,0 \\
\mathrm{~g} \text {, vit. } \mathrm{B}_{6}-3,0 \mathrm{~g} \text {, vit. } \mathrm{B}_{12}-0,015 \mathrm{~g} \text {, ácido nicotínico (nicotinic acid)- } \\
25 \mathrm{~g} \text {, ácido pantotênico (pantothenic acid) } 10 \mathrm{~g} \text {, vit. } \mathrm{K}_{3}-3,0 \mathrm{~g} \text {, ácido } \\
\text { fólico (folic acid)- } 1,0 \mathrm{~g} \text {, bacitracina de zinco (zinc bacitracine) - } 10 \mathrm{~g} \text {, } \\
\text { selênio (selenium) - } 250 \mathrm{mg} \text {, antioxidante BHT (antioxidant BHT) - } 10 \mathrm{~g} \\
\text { e veículo q.s.p. - } 1000 \mathrm{~g} \text {. } \\
2 \text { Conteúdo/kg (Containing/kg): manganês (manganese), } 80 \mathrm{~g} \text {; ferro } \\
\text { (iron), } 80 \mathrm{~g} \text {; zinco (zinc), } 50 \mathrm{~g} \text {; cobre (copper) ; } 10 \mathrm{~g} \text {; cobalto (cobalt), } \\
2 \mathrm{~g} \text {; iodo (iodine), } 1 \mathrm{~g} \text {; e veículo q.s.p., } 500 \mathrm{~g} \text {. }\end{array}$} \\
\hline
\end{tabular}


Rev. bras. zootec.

Tabela 2 - Composição em aminoácidos totais dos ingredientes e totais e digestíveis da ração basal $^{1}$

Table 2 - Composition in total amino acid of ingredients and total and digestible of basal diet

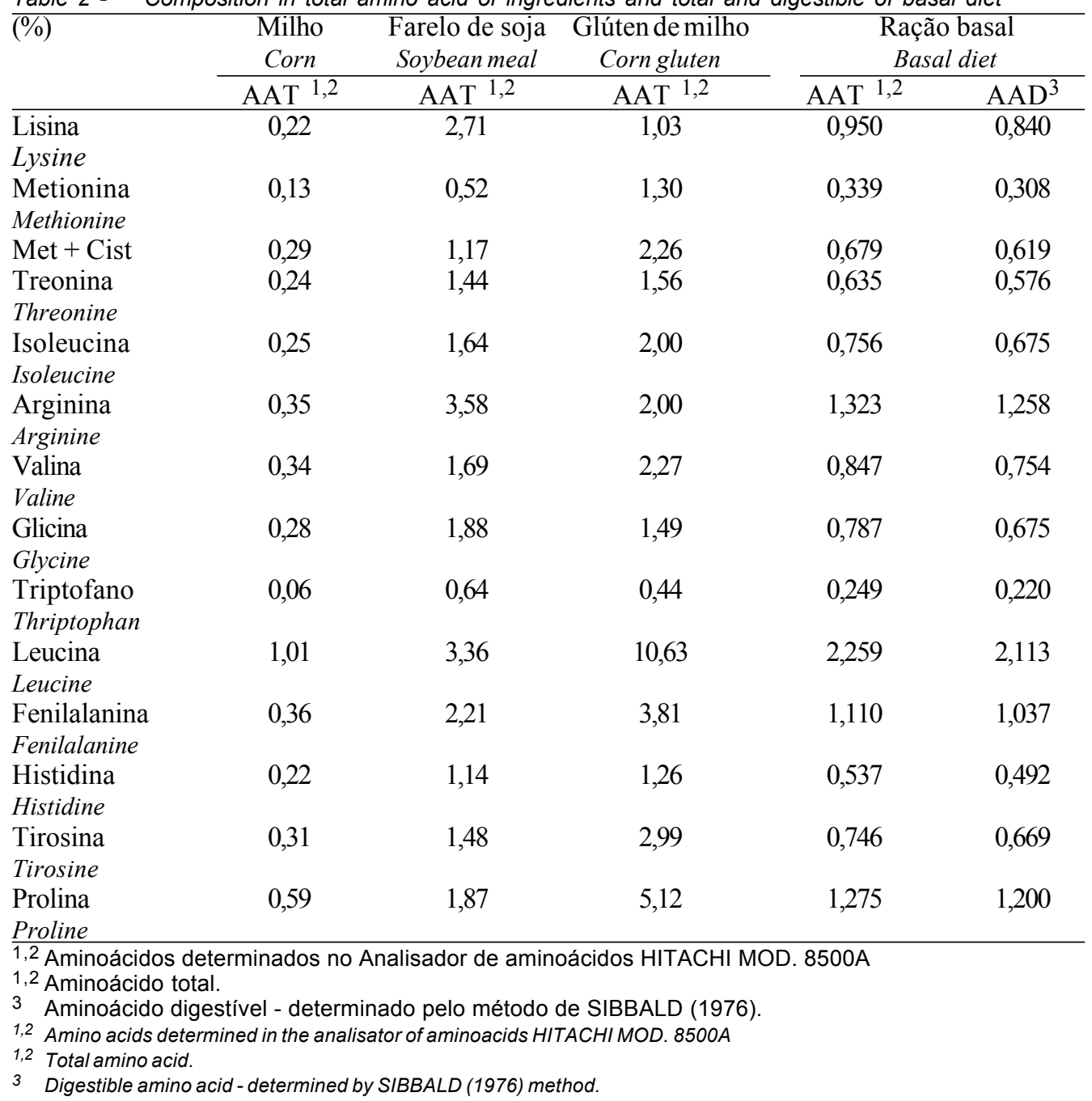

digestibilidade, utilizando-se oito galos Leghorn cecectomizados com peso médio de $2459 \mathrm{~g}$, sendo que quatro receberam a ração basal e quatro permaneceram em jejum durante todo o período experimental. Empregou-se o método da alimentação precisa ou alimentação forçada, desenvolvido por SIBBALD (1976); o período de jejum, a quantidade fornecida de ração e o período de coletada das excretas seguiram a metodologia descrita por PUPA (1995). As excretas recolhidas diariamente foram armazenadas em frascos de vidro com tampas e colocadas em freezer $\left(-10^{\circ} \mathrm{C}\right)$ para análise posterior.

As análises dos aminoácidos na ração basal, nos ingredientes (milho, farelo de soja e glúten de milho) e nas excretas, foram realizadas no Laboratório da Guabi - Mogiana Alimentos S/A - Campinas, SP, utilizando-se analisador de aminoácidos HITACHI modelo $8500 \mathrm{~A}$.

No $21^{\circ}$ dia, foram avaliados o ganho de peso, o consumo de ração, a conversão alimentar e o consumo de lisina dos pintinhos submetidos aos diferentes tratamentos.

No $22^{\circ}$ dia, foram coletadas amostras de sangue, utilizando-se três aves de cada unidade experimental, para análise de ácido úrico no soro sangüíneo. A metodologia utilizada para padronizar o nível de ácido úrico na corrente sangüínea foi a seguinte: pela manhã, retirada da ração por uma hora, retomada da alimentação por uma hora, depois novamente retirada da ração por uma hora, retomada com alimentação por mais uma hora e finalmente jejum de três horas. Em seguida, o sangue foi coletado via punção cardíaca. A determinação do nível de ácido úrico no soro sangüíneo foi realizado utilizando-se o URICADKIT do laboratório Biolab-Mérieux.

A determinação da composição química da carcaça foi realizada utilizando-se três aves de cada unidade experimental, as quais foram abatidas após jejum de 8 horas. Para determinação dos teores de 
matéria seca, extrato etéreo e proteína bruta, utilizouse a metodologia de SILVA (1990), considerando-se o peso médio das carcaças evisceradas e moídas das três aves de cada unidade experimental.

As taxas de deposição de proteína e gordura nas carcaças foram calculadas comparando-se as composições das carcaças de 20 pintos abatidos no $1^{\circ}$ dia com as obtidas de aves abatidas aos 21 dias de idade. No cálculo final da taxa de deposição de proteína e gordura na carcaça, corrigiu-se o valor encontrado para o peso vivo médio de cada boxe.

Utilizou-se delineamento experimental de blocos casualizados, em que os tratamentos constituíram cinco níveis de lisina digestível $(0,84 ; 0,93 ; 1,02 ; 1,11$ e $1,20 \%$ ), com seis repetições e 20 aves por unidade experimental.

As análises estatísticas das características estudadas foram realizadas utilizando-se o programa de sistema para análise estatística e genética (SAEG, 1997), enquanto as estimativas de exigência de lisina digestível foram estabelecidas por meio de modelos de regressão linear e quadrático.

\section{Resultados e Discussão}

Na Tabela 3 são apresentados os resultados de desempenho, consumo de lisina e nível de ácido úrico no soro sangüíneo de pintos de corte alimentados com diferentes níveis de lisina digestível no período de 1 a 21 dias de idade.

Houve efeito quadrático $(\mathrm{P}<0,01)$ dos níveis de lisina digestível sobre o ganho de peso das aves, que aumentou até o nível de $1,05 \%$, correspondente a consumo estimado de $12,40 \mathrm{~g}$ de lisina digestível, conforme a equação $\hat{\mathrm{Y}}=-882,33+3084,46 \mathrm{X}$ 1461,54X2 (Tabela 3 e Figura 1). Estes resultados estão em conformidade com os obtidos por HAN e BAKER (1991), SURISDIARTO e FARRELL (1991), HOLSHEINER e RUESINK (1993) e KIDD et al. (1997), que também observaram variação no ganho de peso das aves, em razão da variação no nível de lisina da ração. O fato de a lisina ser um dos aminoácidos essenciais mais eficientemente utilizado na deposição de proteína corporal(BATTERHAM et al., 1990 eBAKER, 1991) explica a relação verificada entre o nível de lisina da ração e o ganho de peso das aves.

Analisando as relações entre a lisina e os aminoácidos metionina, treonina e triptofano das rações experimentais, considerados mais críticos para as aves, constatou-se que o nível estimado de lisina digestível que proporcionou o melhor resultado de ganho de peso $(1,05 \%)$ ocorreu mais próximo ao da ração $(1,02 \%)$, cujas relações entre esses aminoácidos corresponderam a 33\% metionina, $61 \%$ treonina e $15 \%$ triptofano. Estes valores estão próximos aos estabelecidos como ideais por BAKER e HAN (1994), cujos valores correspondem a $36 \%$ de metionina, $67 \%$ de treonina e $16 \%$ de triptofano.

Portanto, a variação nos resultados de ganho de peso refletiu o efeito do desequilíbrio de aminoácidos na dieta. Segundo HARPER e ROGERS (1965), o desequilíbrio é uma mudança no padrão dos

Tabela 3 - Efeito dos níveis de lisina digestível sobre desempenho, consumo de lisina e ácido úrico no soro sangüíneo de pintos de corte de 1 a 21 dias de idade ${ }^{1}$

Table 3 - Effect of digestible lysine levels on performance, lysine intake and uric acid in the blood serum of broilers from 1 to 21 days of age

\begin{tabular}{|c|c|c|c|c|c|c|}
\hline $\begin{array}{l}\text { Lisina } \\
\text { total } \\
\text { Total lysine } \\
(\%)\end{array}$ & $\begin{array}{l}\text { Lisina dig. } \\
\text { Dig. lysine } \\
(\%)\end{array}$ & $\begin{array}{c}\text { Ganho de } \\
\text { peso } \\
\text { Weight gain } \\
\text { (g) }\end{array}$ & $\begin{array}{l}\text { Consumo } \\
\text { de ração } \\
\text { Ration intake } \\
\text { (g) }\end{array}$ & $\begin{array}{c}\text { Conversão } \\
\text { alimentar } \\
\text { Feed:gain ratio } \\
\text { (g/g) }\end{array}$ & $\begin{array}{c}\text { Consumo } \\
\text { de lisina } \\
\text { Lysine intake } \\
\text { (g) }\end{array}$ & $\begin{array}{l}\text { Ácido } \\
\text { úrico } \\
\text { Uric acid } \\
(\mathrm{mg} / \mathrm{dL})^{1}\end{array}$ \\
\hline 0,95 & 0,84 & 672 & 1166 & 1,74 & 9,79 & 4,80 \\
\hline 1,05 & 0,93 & 740 & 1191 & 1,61 & 11,07 & 4,82 \\
\hline 1,15 & 1,02 & 731 & 1181 & 1,62 & 12,05 & 4,66 \\
\hline 1,25 & 1,11 & 743 & 1208 & 1,63 & 13,41 & 4,80 \\
\hline 1,35 & 1,20 & 715 & 1199 & 1,69 & 14,39 & 4,94 \\
\hline Lisina dig. & & $*$ & n.s. & $* *$ & $* * *$ & n.s. \\
\hline \multicolumn{7}{|c|}{ Digestible lysine } \\
\hline $\mathrm{CV}(\%)$ & & 5,13 & 5,26 & 6,65 & 5,38 & 19,25 \\
\hline
\end{tabular}

${ }^{*} \mathrm{e}^{\star \star}$ Efeito quadrático $(\mathrm{P}<0,01)$ e $(\mathrm{P}<0,05)$ respectivamente.

$\star * \star \quad$ Efeito linear $(P<0,001)$.

n.s.: não-significativo pelo teste $\mathrm{F}$.

1 Concentração padrão, $6.000 \mathrm{mg} / \mathrm{dL}$ - Valor normal $0.00-2000 \mathrm{mg} / \mathrm{dL}$.

${ }^{*}$ and ${ }^{* *}$ Quadract effect $(P<.01)$ and $(P<.05)$, respectively.

*** $\quad$ Linear effect $(P<.001)$.

n.s. $\quad$ no significance by $F$ test.

1 Standard concentration, $6,000 \mathrm{mg} / \mathrm{dL}$ - Normal value $0,00-2000 \mathrm{mg} / \mathrm{dL}$. 


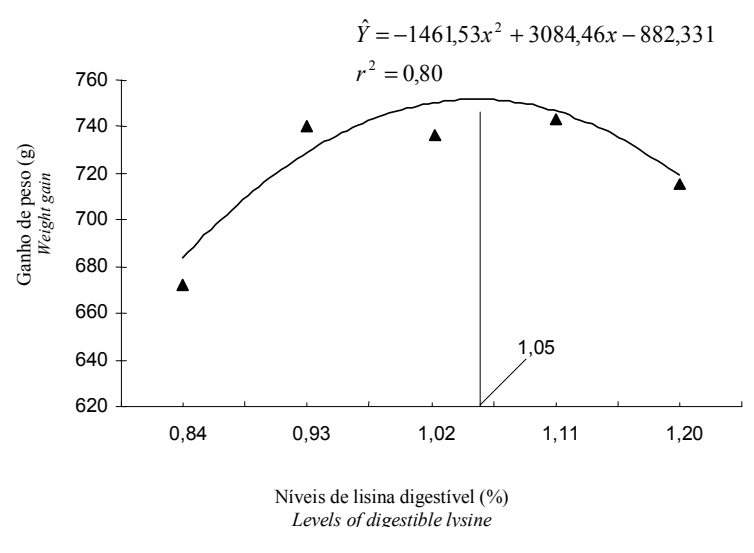

Figura 1 - Níveis de lisina digestível e ganho de peso de pintos de corte machos no período de 1 a 21 dias de idade.

Figure 1 - Levels of digestible lysine and weight gain of male broilers from 1 to 21 days.

aminoácidos da dieta, cujo resultado é caracterizado por redução no crescimento e consumo.

Com relação ao consumo de ração, não se verificou variação em razão do nível de lisina, revelando que o desequilíbrio de aminoácidos ocasionado pelas alterações nos níveis de lisina não foi suficiente para influenciar negativamente essa característica. Estes resultados foram semelhantes aos obtidos por WALDROUP et al. (1976) e COLNAGO e JENSEN (1992).

Verificou-se efeito quadrático $(\mathrm{P}<0,05)$ dos níveis de lisina da ração sobre conversão alimentar (CA) das aves, que melhorou até o nível de 1,03\% de lisina digestível, correspondente a consumo estimado de $12,17 \mathrm{~g}$, conforme a equação $\hat{\mathrm{Y}}=5,146-6,862 \mathrm{X}$ $+3,321 X^{2}$ (Tabela 3 e Figura 2). O nível correspondente de lisina total de $1,16 \%$, que proporcionou os melhores resultados de conversão alimentar, ficou abaixo dos 1,21 e 1,18\% obtidos por HAN e BAKER (1991) e Barbosa, (1996), citado por ROSTAGNO etal. (1996), e próximo aos obtidos por ROSTAGNO et al. (1996), de $1,165 \%$ de lisina total. Os piores valores de CA verificados nos níveis extremos de lisina $(0,84$ e $1,20 \%)$ podem estar relacionados ao gasto extra de energia para catabolizar os aminoácidos em excesso.

Não foram observadas variações significativas do nível de ácido úrico no soro sangüíneo das aves, em razão dos níveis de lisina da ração. Associando os resultados de desempenho com os de ácido úrico no soro sangüíneo das aves, pode-se inferir que a determinação desse ácido não se constituiu em parâmetro apropriado para estabelecer a exigência de lisina das aves no período de 1 a 21 dias de idade.

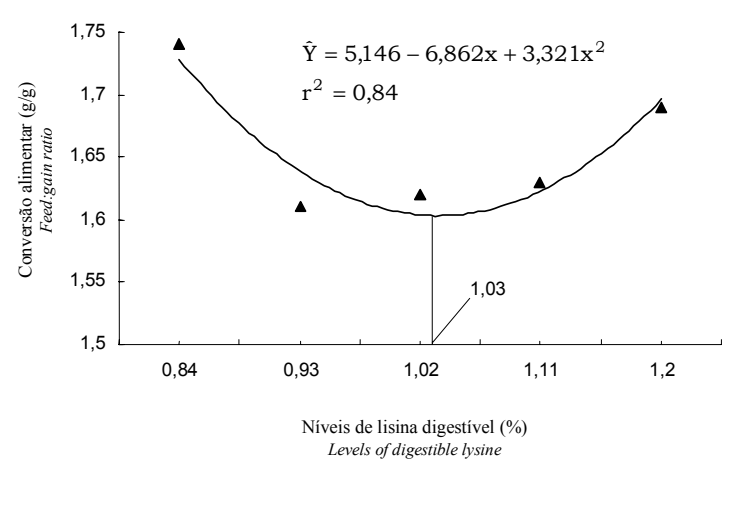

Figura 2 - Níveis de lisina digestível e conversão alimentar de pintos de corte machos no período de 1 a 21 dias de idade.

Figure 2 - Levels of digestible lysine and feed:gain ratio of male broilers from 1 to 21 days.

Os resultados de composição química e taxa de deposição de proteína e gordura na carcaça dos frangos abatidos com 21 dias de idade são apresentados na Tabela 4.

Quanto à composição química da carcaça, não se constatou efeito dos níveis de lisina digestível da ração sobre os teores de matéria seca e proteína bruta, mas houve efeito linear $(\mathrm{P}<0,02)$ sobre a porcentagem de extrato etéreo, conforme a equação $\hat{Y}=12,355+0,8728 X$ (Tabela 4 e Figura 3). Houve efeito quadrático dos níveis de lisina na ração sobre a taxa de deposição de proteína $(\mathrm{P}<0,002)$ e gordura $(\mathrm{P}<0,001)$ na carcaça. A taxa de deposição de proteína elevou-se até o nível de 1,08\% de lisina digestível, segundoa equação $\hat{Y}=-118,025+383,436 X-178,832 X 2$ (Tabela 4 e Figura 4), ao passo que a taxa de deposição de gordura aumentou até o nível de 1,04\% de lisina digestível, conforme a equação $\hat{Y}=-194,444+525,234 X$ - 251,493X2 (Tabela 4 e Figura 5).

Pode-se inferir que as taxas de deposição de proteína e gordura na carcaça de frangos estão correlacionadas, sendo a exigência de lisina digestível para deposição de proteína $(1,08 \%)$ superior à exigência para ganho de peso $(1,05 \%)$ e deposição de gordura $(1,04 \%)$. Estes resultados são semelhantes aos obtidos por SIBBALD e WOLYNETZ (1986), que observaram nível menor de lisina na ração para maximizar o ganho de peso corporal que aquele para otimizar a agregação de proteína.

Os resultados de aumento nas taxas de deposição de proteína (TDP) e gordura (TDG) na carcaça, associados ao aumento no nível de lisina na ração, foram semelhantes aos obtidos por 


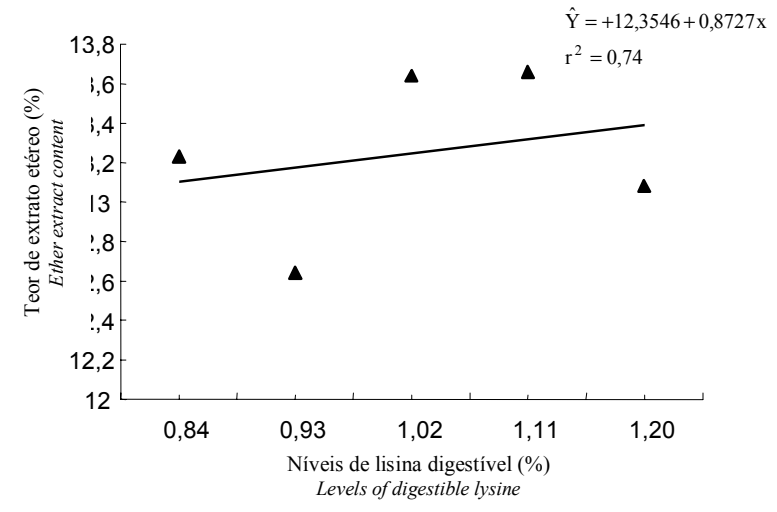

Figura 3 - Níveis de lisina digestível e teor de extrato etéreo na carcaça de pintos de corte machos no período de 1 a 21 dias de idade.

Figure 3- Levels of digestible lysine ether extract content in the carcass of male broilers from 1 to 21 days.

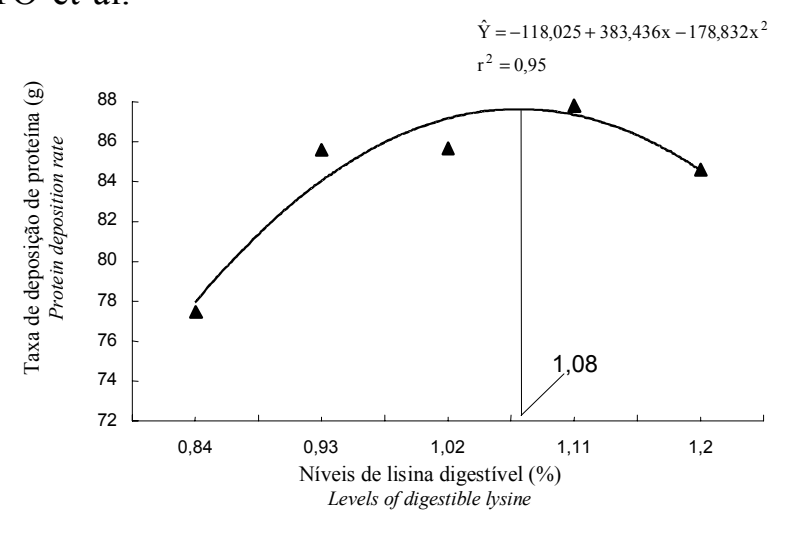

Figura 4 - Níveis de lisina digestível e taxa de deposição de proteína na carcaça de pintos de corte machos no período de 1 a 21 dias de idade.

Figure 4- Levels of digestible/ysine and protein deposition rate in the carcass of male broilers from 1 to 21 days.

Tabela 4 - Efeito dos níveis de lisina digestível sobre composição química da carcaça e taxa de deposição de proteína e gordura na carcaça de pintos de corte ${ }^{1}$

Table 4 - Effect of digestible lysine levels on the carcass chemical composition and protein and fat deposition rate in the carcass of broilers ${ }^{1}$

\begin{tabular}{|c|c|c|c|c|c|c|}
\hline Lisina dig. & MS & Água & PB & $\mathrm{EE}$ & Tx. dep. de prot. ${ }^{2}$ & Tx. dep de gord. \\
\hline $\begin{array}{l}\text { Dig. lysine } \\
(\%)\end{array}$ & $\begin{array}{l}D M \\
(\%)\end{array}$ & $\begin{array}{l}\text { Water } \\
(\%)\end{array}$ & $\begin{array}{l}C P \\
(\%)\end{array}$ & $(\%)$ & $\begin{array}{l}\text { Protein dep. rate } \\
(\mathrm{g})\end{array}$ & $\begin{array}{l}\text { Fat dep. rate } \\
\text { (g) }\end{array}$ \\
\hline$\overline{0,84}$ & 32,43 & 67,57 & 14,93 & 13,23 & 77,42 & 69,49 \\
\hline 0,93 & 31,93 & 68,08 & 15,66 & 12,63 & 85,61 & 75,74 \\
\hline 1,02 & 32,10 & 67,91 & 14,57 & 13,64 & 85,66 & 80,60 \\
\hline 1,11 & 32,01 & 67,99 & 14,62 & 13,66 & 87,80 & 77,93 \\
\hline 1,20 & 31,44 & 68,56 & 14,62 & 13,08 & 84,59 & 73,93 \\
\hline $\begin{array}{l}\text { Lisina dig. \% } \\
\text { Dig. lysine }\end{array}$ & n.s. & n.s. & n.s. & $*$ & $* *$ & $* *$ \\
\hline $\mathrm{CV}(\%)$ & 2,69 & 1,26 & 4,41 & 7,08 & 3,30 & 3,75 \\
\hline
\end{tabular}

${ }^{*} e^{* *}$ Efeito quadrático $(P<0,01)$ e $(P<0,05)$ respectivamente.

*** Efeito linear $(P<0,001)$.

n.s.: não-significativo pelo teste $\mathrm{F}$.

1 Concentração padrão, $6000 \mathrm{mg} / \mathrm{dL}$ - Valor normal $0,00-2000 \mathrm{mg} / \mathrm{dL}$.

* and ** Quadract effect $(P<.01)$ and $(P<.05)$, respectively.

*** $\quad$ Linear effect $(P<.001)$.

n.s. $\quad$ no significance by $F$ test.

1 Standard concentration, $6000 \mathrm{mg} / \mathrm{dL}$ - Normal value $0.00-2000 \mathrm{mg} / \mathrm{dL}$.

HOLSHEIMER e RUESINK (1993), constatando-se que a maior deposição de proteína e gordura na carcaça foi obtida com alto nível de lisina na ração. Todavia, neste trabalho, o consumo de energia variou pouco entre os tratamentos, não comprometendo, assim, a taxa de deposição de proteína e gordura. Entretanto, a TDP e a TDG refletiram a resposta do ganho de peso. 
Rev. bras. zootec.

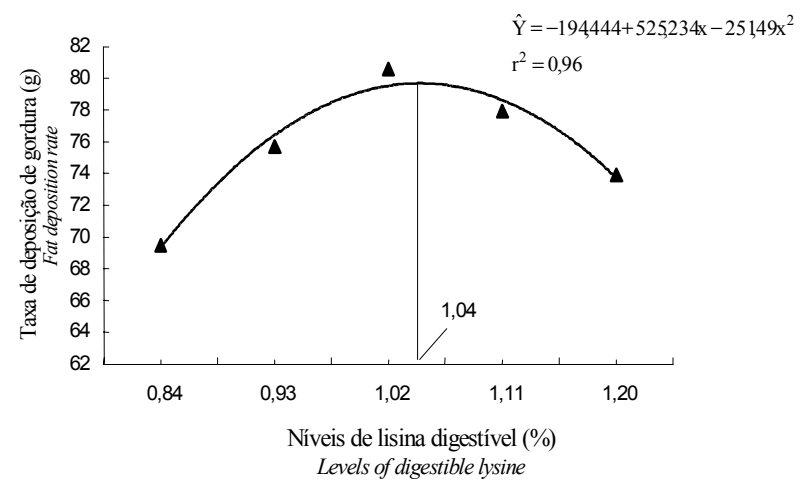

Figura 5 - Níveis de lisina digestível e taxa de deposição de gordura na carcaça de pintos de corte machos no período de 1 a 21 dias de idade.

Figure 5 - Levels of digestible lysine and fat deposition rate in the carcass of male broilers from 1 to 21 days.

\section{Conclusões}

Com base nos resultados de ganho de peso (GP), conversão alimentar (CA) e taxa de deposição de proteína na carcaça, pode-se concluir que a exigência de lisina digestível na ração da fase inicial de criação de frangos de corte machos ( 1 a 21 dias) situa-se em faixa de 1,03 a $1,08 \%$.

\section{Referências Bibliográficas}

BAKER, D. H. 1991. Partitioning of nutrients for growth and other metabolic functions. Poult. Sci., 70:1797-1805.

BAKER, D. H., HAN, Y. 1994. Ideal amino acid profile for chicks during the first three weeks posthatching. Poult. Sci., 73: 1441-1447.

BATTERHAM, E. S., ANDERSON, L. M., BAIGENT, D. R. et al. 1990. Utilization of ileal digestible amino acids by growing pigs: effect of dietary lysine concentration on efficiency of lysine retention. Br. J. Nut., 31:237, 1990.

COLNAGO, G. L., JENSEN, L. S. 1992. Putrescine effects on performance of male broiler chicks fed low-protein diets supplemented with essential amino acids. Poult. Sci., 71:211-214.
HAN, Y., BAKER, D. H. 1991. Lysine requirements of fast-andslow growing broiler chicks. Poult. Sci.,70:2108-2114.

HARPER, A. E., ROGERS, Q. R. 1965. Amino acid imbalances. Proceedings of Nutrition Society, 24:173-190.

HOLSHEINER, J. P., RUESINK, E. W. 1993. Effect on performance, carcass composition, yield and financial return of dietary energy and lysine levels in starter and finisher diets fed to broilers. Poult. Sci., 72:806-815.

KIDD, M. T., KERR, B. J., ANTHONY, N. B. 1997. Dietary interactions between lysine and threonine in broilers. Poult. Sci., 76:608-614.

NATIONAL RESEARCH COUNCIL - NRC 1994. Nutrients Requirements of Poultry. 9. ed. National Academic Press, Washington, D.C. 155 p.

PUPA, J. M. R. Rações para frangos de corte formuladas com valores de aminoácidos digestíveis verdadeiros, determinados com galos cecectomizados. Viçosa, MG: UFV, 1995. 63p. Dissertação (Mestrado em Zootecnia) - Universidade Federal de Viçosa, 1995.

ROSTAGNO, H. S., SILVA, D. J., COSTA, P. M. A. et al. 1983. Composição de alimentos e exigências nutricionais de aves e suínos (tabelas brasileiras). Viçosa-MG: Imprensa Universitária. $60 \mathrm{p}$.

ROSTAGNO, H. S., BARBARINO JR., P., BARBOZA, W. A. Exigências nutricionais das aves determinadas no Brasil. In: SIMPÓSIO INTERNACIONAL SOBRE EXIGÊNCIAS NUTRICIONAIS DE AVES E SUÍNOS, Viçosa, MG, 1996. Anais... UFV: DZO, 1996. p. 361-388.

SAEG - Sistema para análise estatística e genética, Versão 7.0, Viçosa, MG: Fundação Arthur Bernardes,1997.

SIBBALD, J. R. 1976. A biossay for true metabolizable energy in feedingstuffs. Poult. Sci., 55:303- 308.

SIBBALD, J. R., WOLYNETZ, M.S. 1986. Effects of dietary lysine and feed intake on energy utilization and tissue synthesis by broiler chicks. Poult. Sci., 65:98-105.

SILVA, D. J. 1990. Análise de Alimentos (Métodos químicos e biológicos). Viçosa: Imprensa Universitária. $160 \mathrm{p}$.

SURISDIARTO, FARRELL, D. J. 1991. The relationship between dietary crude protein and dietary lysine requirement by broiler chicks on diets with and without the "ideal" amino acids balance. Poult. Sci., 70:830-836.

WALDROUP, P.W., MITCHEL, R.J., PAYNE, J.R. et al. 1976. Performance of chicks fed diets formulated to minimize excess levels of essential amino acids. Poult. Sci., 55:243 - 253.

Recebido em: 04/02/98 Aceito em: 16/07/98 